\title{
Manufacturing of concrete elements on mobile polygons with the using of solar energy
}

\author{
Dmitry D. Koroteev, Makhmud Kharun*, Nadezhda A. Stashevskaya
}

Department of Civil Engineering, RUDN University, Moscow, Russia

\section{A R T I C LE IN F O}

\section{Article history:}

Received 15 January 2017

Received in revised form

25 July 2017

Accepted 26 July 2017

\section{Keywords:}

Manufacturing of concrete

Mobile polygons

Solar energy

Organizational solutions

Technological solutions

\begin{abstract}
A B S T R A C T
The aim of the research work is to study methods, which can allow sustainable and reliable manufacturing of concrete elements with the use of solar energy. The first method is determination of reasonability and time of effective employment of solar energy subject to climatic characteristics of the manufacturing area. The second method is prediction of the probability of reduction of the solar insolation in the estimated manufacturing period. The third method is reservation of additional material resources to increase parameters of reliability and stability of the manufacturing. It is necessary to use these methods as comprehensive approach. The research results allow reducing costs for manufacturing of concrete elements as compared with traditional technology and getting the finished products with keeping the specified work schedule. It is especially important for mobile polygons (mobile building sides), which are used to quick arrangement of manufacturing of concrete elements, including timely reconstruction works in the location of the occurred catastrophe in conditions of destroyed industry, unavailability of providing energy and material recourses.
\end{abstract}

(C) 2017 The Authors. Published by IASE. This is an open access article under the CC BY-NC-ND license (http://creativecommons.org/licenses/by-nc-nd/4.0/).

\section{Introduction}

World civilization has faced unexpected phenomenon of technological and natural catastrophes in recent time. In many cases, they occur in locations, which are far from technical and energy facilities. Technological and natural catastrophes are connected with partial or total destruction of infrastructure, engineering networks and communications, civil and industrial buildings. The administration of locations, where the catastrophe occurred, carries out rescue and recovery work, which aim is protection of the population, providing them all necessary living conditions, and reconstruction of infrastructure. Government deliveries all necessary materials, constructions and machines from other locations by various transport facilities in conditions of destroyed industry, unavailability of providing energy and material recourses with high financial and material expenses.

In the crisis cases, which take place during the catastrophes, vital problem is organization of

\footnotetext{
* Corresponding Author.

Email Address: miharun@yandex.ru (M. Kharun)

https://doi.org/10.21833/ijaas.2017.010.002

2313-626X/@ 2017 The Authors. Published by IASE.

This is an open access article under the CC BY-NC-ND license

(http://creativecommons.org/licenses/by-nc-nd/4.0/)
}

building construction with local materials in short time. Mobile polygons (mobile building sites) can be used for this purpose. Mobile polygons are organized to manufacture concrete constructions for timely reconstruction work in the location of the occurred catastrophe. Their main advantages are the following: possibility of manufacturing of various constructions, including custom sizes; short time of preliminary works; insignificant capital investments for their organization. Organization of mobile polygon includes installation of mobile concrete mixing plant on site and delivery formworks and other equipment for manufacturing of concrete. Capacity of mobile concrete mixing plant is $60-130$ $\mathrm{m}^{3}$ per hour depending on model. Another vital problem along with manufacturing of concrete elements in short time is reducing costs in conditions of destroyed energy facilities. One of the ways of cost reduction is using renewable resources such as solar, geothermal and wind energy.

\section{Analysis of the stated issue}

Thermal treatment of concrete is one of the most effective ways to accelerate the curing process and, as a rule; it is an essential part in manufacturing of the reinforced concrete elements. For the plants with production capacity of $20,000 \mathrm{~m}^{3}$ the fossil fuel consumption is $100-300$ tons per year, and $250-700$ 
tons for the plants with production capacity of $50,000 \mathrm{~m}^{3}$. Meanwhile, 0.1-0.2 petroleum equivalent is consumed to manufacture $1 \mathrm{~m}^{3}$ of reinforced concrete structures (Krilov et al., 2005).

Concrete is heated up to $60-80{ }^{\circ} \mathrm{C}$ during its thermal treatment. The possibility of obtaining such temperatures in the solar energy equipment allows using the solar energy for thermal treatment of concrete.

Since the mid-20th century, the research on development of different types of solar energy equipment has been carried out in different countries. The most common types are the solar energy equipment like solar collector and hotbox.

The energy assessment and detailed specification of the structure of solar energy equipment are presented in works (Podgornov, 2010; Podgornov and Koroteev, 2007).

Solar collectors are widely used in different fields, such as household equipment systems (Dongellini et al., 2015), hot water production (Zhang et al., 2015). The solar energy equipment like solar collector is formwork equipped with the transparent cover (Fig. 1). Direct heating of concrete by solar energy takes place in such equipment.

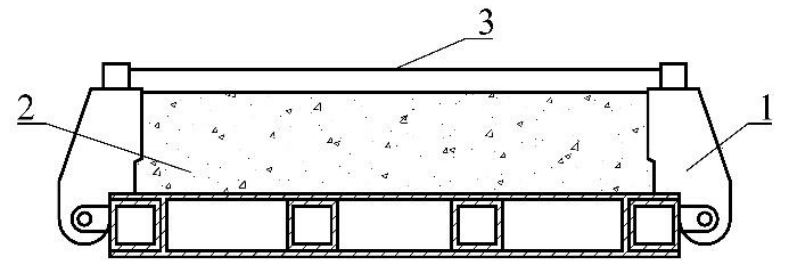

Fig. 1: Concept of formwork with transparent cover (1formwork, 2-concrete, 3-transparent cover)

The solar energy equipment like hotbox is a rectangular metallic container without bottom with the transparent cover, fixed around it, and the thermal insulation of container, oriented to the North (Fig. 2). The heat receiving material, which absorbs solar radiation and becomes the energy source, is placed inside of the solar energy equipment.

\section{Ways of using solar energy}

Introduction of new technology of concrete elements manufacturing on mobile polygons, connected with employment of renewable resources as energy source for the thermal treatment of concrete, is possible only under condition of guarantee their reliable and sustainable work.

The reliability of production consists of probability of the receipt of the product with specified parameters of quality in fixed volume and period.

The efficiency of technological process can change in wide range depending on level of consideration of all particular production conditions. In this regard, topical problem is organization of concrete elements manufacturing, using solar energy, on mobile polygons with forecasting and improvement of reliability of its main parameters.
The manufacturing of concrete elements is a complex dynamic system with set of connections, which provides cooperation between its elements in space and time. The reliability of this system increases with growth of the production organization level, which depends on reliability of each element of the system and reliability of their cooperation. Basic concept of reliability theory is a concept of failure. It means utter or partial failure of the system.

All failures have the random nature, because they are caused by influence of random factors. The reliability of the system is determined by reliability of failure during the guarantee period of the system work.

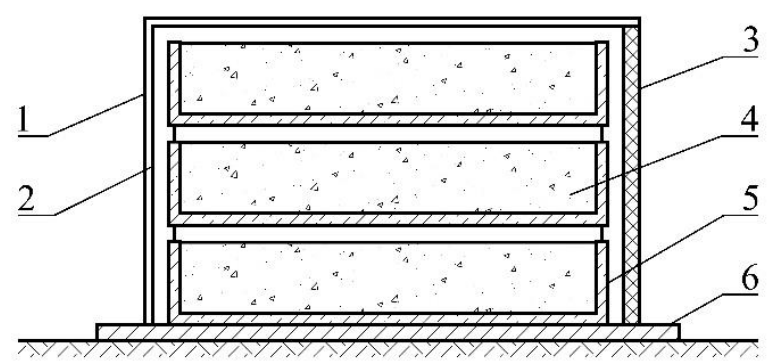

Fig. 2: Concept of the hotbox solar energy equipment (1transparent cover, 2-metal container, 3-thermal

insulation of the container's part, oriented to the North, 4concrete, 5-formwork, 6-stand)

The reliability of concrete elements manufacturing with employment of solar energy on mobile polygons is determined by the reliability of providing the finished products with keeping the specified work schedule. Solar energy is nonstationary energy resource for technological purposes. It connects with deterministic processes of rotation of the earth around the sun and its axis and stochastic processes, taking place in atmosphere (cloud, circulating air).

The manufacturing of concrete constructions means constant consumption of energy for heat treatment of concrete. In this connection, first, it is necessary to settle organizational and technological problem of sustainable and reliable manufacturing of concrete constructions with employment of solar energy, taking into account spatial and time changes of its flow on the surface of the earth. The main stages of settling of the above problem are the following:

1.Determination of reasonability and time of effective employment of solar energy subject to climatic characteristics of the location, where we assume to organize mobile polygon.

2. Prediction of the probability of reduction of the solar insolation in the estimated period of mobile polygon operation.

3. Reservation of additional material resources to increase parameters of reliability and stability of the manufacturing in the period of mobile polygon operation. 


\section{Time of effective employment of solar energy}

The determination of solar energy sufficiency and time of its effective using bases on the determination of temperature and time parameters of concrete and kinetics of its curing in the result of modeling of the process of thermal treatment in the solar energy equipment.

The parameter of solar energy sufficiency for thermal treatment of concrete constructions is concrete strength, which allows dismantling formwork, transporting and storing the constructions with saving of the technological period of their manufacturing (Podgornov and Koroteev, 2011).

Source data for modeling of the process of the thermal treatment of concrete is climatic characteristics of the building site and information about product range.

The main technological parameters during manufacturing of concrete elements are the manufacturing period $\left(T_{m}\right)$, strength of concrete after manufacturing $\left(R_{m}\right)$, the manufacturing costs $\left(C_{m}\right)$ in energy and economic equivalent. The most reasonable option for assessment of the production organization level is option, which has minimum manufacturing costs (Eq. 1).

$$
\left\{\begin{array}{c}
R_{m}=\text { const } \\
T_{m}=\text { const } \\
C_{m 1}-C_{m 2} \triangleright 0
\end{array}\right.
$$

where $C_{m 1}$ - cost of using fossil fuels; $C_{m 2}$-cost of using renewable resources.

If intensity of solar energy goes down, the manufacturing period will increase. In this case, time of effective employment of solar energy is determined by time, when costs, connected with growth oh the manufacturing period, will be less than costs of using fossil fuels (Eq. 2).

$\left\{R_{m}=\right.$ const

$\left\{C_{T 2}-C_{T 1} \triangleleft C_{m 1}-C_{m 2}\right.$

where $C_{T 1}$-cost during the manufacturing period with employment of fossil fuels; $C_{T 2}$-cost during the manufacturing period with employment of renewable resources.

\section{Prediction of reduction of the solar insolation}

It is necessary to take into account stochastic nature of processes in atmosphere by modeling daily changes of solar insolation in the estimated period to provide reliable and sustainable manufacturing of concrete elements on mobile polygons with employment of solar energy.

The source stochastic data for modeling is statistic information about frequency of sunny and cloudy days by months.

Probability of effective work of the polygon, i.e. providing of the necessary manufacturing period, depending on weather conditions, in the specified month can be determined by Eq. 3 .

$P\left(M_{i}\right)=\frac{N_{\text {days }}-N_{\text {cloudy }}}{N_{\text {days }}}$

where $N_{\text {days }}$-the number of days in the specified month; $N_{\text {cloudy }}$-the average number of cloudy days in the specified month.

Probability of effective work of the polygon during the season of reasonable employment of solar energy for thermal treatment of concrete can be determined by Eq. 4 .

$\mathrm{P}\left(\sum_{\mathrm{i}=1}^{\mathrm{n}} \mathrm{M}_{\mathrm{i}}\right)=\frac{\sum_{\mathrm{i}=1}^{\mathrm{n}} \mathrm{P}\left(\mathrm{M}_{\mathrm{i}}\right)}{\mathrm{n}}$

where $M_{1}, M_{2}, \ldots, M_{n}$-months in a year, when it is reasonable to use solar energy for the thermal treatment of concrete elements on the polygon; $P\left(M_{1}\right), P\left(M_{2}\right), \ldots, P\left(M_{n}\right)$-probabilities of effective work of the polygon in the specified months.

Coefficient of readiness, i.e. probability of reliable work of manufacturing system in randomly chosen day from the specified period of the polygon operation is determined by Eq. 5 .

$K_{R}=\frac{N_{\text {sunny }}}{N_{\text {period }}}$

where $N_{\text {sunny }}$-the average number of sunny days in the specified period of the polygon operation; $N_{\text {period }}{ }^{-}$ the specified period of the polygon operation.

The solar energy intensity reduces in 1.2-1.5 times during cloudy weather and it comes to the solar perceiving surface as scattered radiation. In the result, the period of concrete curing increases and the plant cannot provide the manufacturing schedule. Coefficient of downtime, i.e. probability of unreliable work of manufacturing system in randomly chosen day from the specified period of the polygon operation is determined by Eq. 6 .

$K_{D}=\frac{N_{\text {cloudy }}}{N_{\text {period }}}=1-K_{R}$

where $N_{\text {cloudy }}$ - the average number of cloudy days in the specified period of the polygon operation.

The probability of weather deterioration, characterized by total uncertainly of its appearance, is determined based on statistics of frequency of sunny and cloudy days and prediction of the trend in time.

\section{Reliability improvement}

It is necessary to reserve resources depending on value of the estimated coefficient of readiness to provide reliability of the manufacturing system.

The improvement of the reliability parameter increases costs for reservation of the manufacturing elements, but decreases product cost due to improvement of the system readiness and rise of manufacturing value in unit of time. One of the ways of reliability improvement of the mobile polygon 
operation is short-term, daily and seasonal accumulation of solar energy in heat accumulating materials.

Daily and short-term accumulation is associated with heat accumulation during the daytime and covering expenses for thermal treatment of concrete in the nighttime with aim of providing of the manufacturing schedule.

The seasonal accumulation is carried out for long period of bad weather conditions. The main heat receivers for accumulation of solar energy are the following:

- Solar collectors for heating of air and water;

- Concrete slabs, manufactured for batch technology;

-Water and stones, which are the most energyintensive components of concrete mix.

If we want to increase concrete temperature by 1 ${ }^{\circ} \mathrm{C}$, we need to increase cement temperature by $8-10$
${ }^{\circ} \mathrm{C}$ or water temperature by $4{ }^{\circ} \mathrm{C}$ or stones temperature by $1.6-1.8^{\circ} \mathrm{C}$. Therefore, it is reasonable to increase temperature of water and stones firstly.

Water heating is carried out in serial solar collectors. Stones heating is carried out in open warehouses of trench, bunker and silo types with supply through them hot air from air collectors. Appropriate equipment locates in area of storage and preparation of raw materials.

Another way of reliability improvement is using of durable concrete. The durable concrete is concrete with various organic and inorganic compositions as special additives.Kinetic part of energy, embedded in composite binder during its manufacturing, allows modified concrete curing intensively in case of less temperature of thermal treatment than usual. Our Research testifies to the fact that the increase of temperature and intensity of solar radiation does not influence on hardness of modified concrete (Fig. 3).

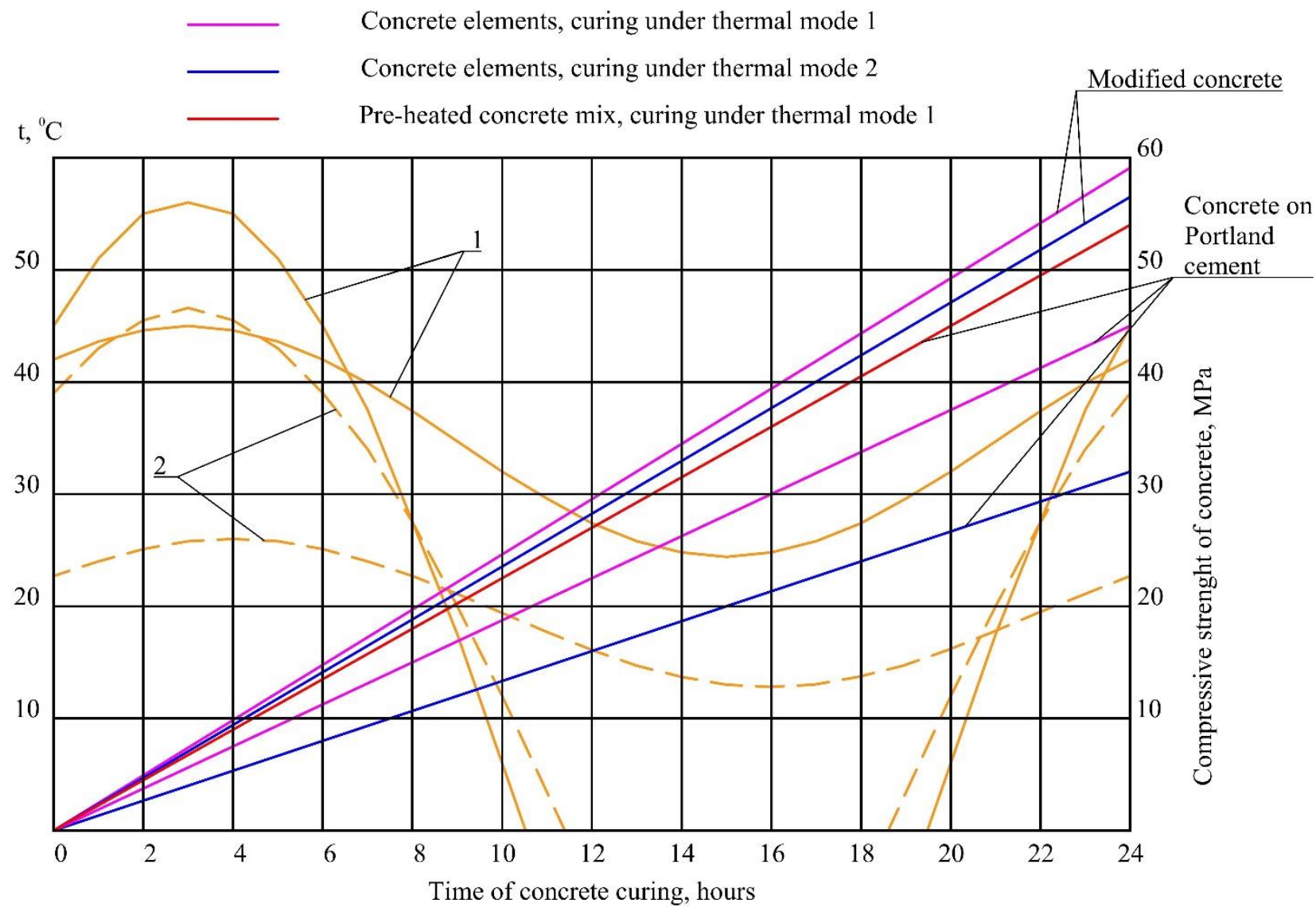

Fig. 3: Strength of concrete, prepared on various compositions and hardening in formworks equipped with transparent cover (1-air temperature and intensity of solar radiation (thermal mode 1); 2-air temperature and intensity of solar radiation (thermal mode 2))

\section{Results and discussion}

Our determination shows that time of effective employment of solar energy for thermal treatment of concrete is 5 months for Moscow region $\left(\varphi=56^{\circ} \mathrm{N}\right)$ and 7 months for South of Russia $\left(\left(\varphi=45^{\circ} \mathrm{N}\right)\right.$. The determination was carried out for concrete elements, curing in formwork equipped with transparent cover. The manufacturing period does not exceed 24 hours during this time.
Reservation of heat in water and stones in the daytime and preparation from them pre-heated concrete mix with temperature of $50-60{ }^{\circ} \mathrm{C}$ intensify concrete curing on 20-30\%. Increase of concrete strength on pre-hearted concrete mixes is explained by reduction of water-cement ratio due to partial water absorption by cement and stones, along with water evaporation. In the future, water, absorbed by materials, contributes to better cement hydration during the curing of concrete. 
In spite of high price of modified concrete, prepared in composite binder with addition of various chemical additives, science research affirmed the technological and economic efficiency of their using (Batrakov, 1998).

The main technological advantages of modified concrete that allows using it as element of the reliability improvement are the following:

- High speed of curing that allows reducing the manufacturing period;

-High fluidity that allows reducing labor input and costs for stowage, leveling and sealing of concrete mix, cutting time for these technological operations in 1.5-2 times (Izotov and Sokolova, 2006).

Practically vibration-free conditions of equipment work provide wide using of easy fast-reconfigurable formworks and fastening of their removable details on easy locks, which are especially actual for the mobile polygons.

Using of modified concrete reduces time of concrete elements manufacturing in 1.5 times and increases time of effective employment of solar energy on 2-3 months in dependence on geographic area of manufacturing, that allows using it as main or backup manufacturing element for providing of readiness of the mobile polygon operation.

\section{Conclusion}

Thus, the above-mentioned organizational and technological solutions contribute to increase of efficiency of concrete elements manufacturing on mobile polygons and active using of renewable resources for recovery and building works during elimination of consequences of technological and natural catastrophes.

It is necessary to consider the economic, social and environmental benefits when comparing the technologies of manufacturing of concrete elements with employment of solar energy and fossil fuels. If we consider the hidden costs of energy resources, the majority of new technologies, that make use of renewable resources, will become competitive with the existing.

\section{References}

Batrakov VG (1998). Modified concrete: Theory and practice. Technoproekt, Moscow, Russia.

Dongellini M, Falcioni S, and Morini GL (2015). Dynamic simulation of solar thermal collectors for domestic hot water production. Energy Procedia, 82: 630-636.

Izotov VS and Sokolova UA (2006). ХИМИЧЕСКИЕ ДОБАВКИ ДЛЯ МОДИФИКАЦИИ БЕТОНА. МОНОГРАФИЯ [Chemical additives for modification of concrete]. Poleotype Publisher, Moscow, Russia. Available online at: https://elibrary.ru/ item.asp?id=20243885

Krilov BA, Abramcumyan SA, and Zvezdov AI (2005). Manual for thermal processing of concrete in monolithic concrete constructions. Scientific Research Institute of Concrete and Reinforced Concrete, Moscow, Russia. Available online at: https://elibrary.ru/item.asp?id=19625732

Podgornov NI (2010). Thermal processing of concrete with using of solar energy. ASV Publisher, Moscow, Russia. Available online at: https://elibrary.ru/item.asp?id=19630332

Podgornov NI and Koroteev DD (2007). Application of thermal treatment procedure for concrete with the help of solar energy to construction engineering practice. Applied Solar Energy, 43(4): 218-222.

Podgornov NI and Koroteev DD (2011). Energy appreciation of employment of solar energy for heat-processing of concrete products. BULLETIN of Russian People's Friendship University. Series Engineering Researches, (2): 48-52. Available online at: http://journals.rudn.ru/engineeringresearches/article/view/5015

Zhang W, Lin K, Yuasa R, and Kato S (2015). Experimental and computational study for household equipment system in a smart House with solar collectors. Energy Procedia, 78: 34283433. 